\title{
POSITIVE SOLUTIONS TO A TWO POINT SINGULAR BOUNDARY VALUE PROBLEM
}

\section{AbDelhamid Benmezai, John R. GRaef and LingJu Kong}

Abstract. We employ fixed point index theory to establish existence results for positive solutions to the singular boundary value problem

$$
\left\{\begin{array}{l}
-\left(a u^{\prime}\right)^{\prime}(t)=b(t) f(t, u(t)), \quad t \in(0,1), \\
u^{\prime}(0)=u(1)=0,
\end{array}\right.
$$

where $a \in C^{1}((0,1),(0, \infty)), 1 / a$ is integrable on any compact subset of $(0,1], b \in C((0,1)$, $[0,+\infty))$ does not vanish identically and is integrable on any compact subset of $[0,1)$, and $f$ : $[0,1] \times \mathbb{R}^{+} \rightarrow \mathbb{R}^{+}$is continuous with $f(t, u)>0$ for all $(t, u) \in[0,1] \times(0, \infty)$. As applications, existence and nonexistence criteria for positive radial solutions to some elliptic equations are deduced.

Mathematics subject classification (2010): 34B15, 34B16, 34B18, $35 \mathrm{~J} 25$.

Keywords and phrases: positive solutions, singular boundary value problems, fixed point index theory, radial solutions.

\section{REFERENCES}

[1] R. P. Agarwal and D. O’Regan, Singular Differential and Integral Equations with Applications, Kluwer Academic Publishers, Boston, 2003.

[2] A. BenMeZAi, On the number of solutions of two classes of Sturm-Liouville boundary value problems, Nonlinear Anal., 70 (2009), 1504-1519.

[3] H. BREZIS AND H. LIEB, A relation between pointwise convergence of functions and convergence of functionals, Proc. Amer. Math. Soc., 88 (1983), 486-490.

[4] M. ChHETRI And S. Robinson, Multiple positive solutions for singular boundary value problems, Comm. Appl. Nonlinear Anal., 14 (2007), 15-29.

[5] K. Deimling, Nonlinear Functional Analysis, Springer-Verlag, Berlin, 1985.

[6] J. M. Do Ó, S. LuCRA, AND P. UBILlA, Three positive radial solutions for elliptic equations in a ball, Appl. Math. Lett., 18 (2005), 1163-1169.

[7] L. H. ERBE, Eigenvalue criteria for existence of positive solutions to nonlinear boundary value problems, Math. Comput. Modelling, 32 (2000), 529-539.

[8] L. H. ERBE AND H. WANG, On the existence of positive solution for semilinear elliptic equation in the annulus, J. Differential Equations, 109 (1994), 1-7.

[9] L. H. ERBE AND H. WANG, On the existence of positive solutions of ordinary differential equations, Proc. Amer. Math. Soc., 120 (1994), 743-748.

[10] L. H. ERBE, S. HU, AND H. WANG, Multiple positive solutions of some boundary value problems, J. Math. Anal Appl., 184 (1994), 640-648.

[11] J. Henderson And H. WANG, Positive solutions for nonlinear eigenvalue problems, J. Math. Anal. Appl., 208 (1997), 252-259.

[12] M. FEnG, X. ZHANG, AND W. GE, New existence theorems of positive solutions for a singular boundary value problem, Electron. J. Qual. Theory Diff. Equ., 13 (2006), 1-9. 
[13] P. FENG, On the structure of positive solutions to an elliptic problem arising in thin film equations, J. Math. Anal. Appl., 370 (2010), 573-583.

[14] D. Guo And V. Lakshmikantham, Nonlinear Problems in Abstract Cones, Academic Press, San Diego, 1988.

[15] K. S. HA AND V. H. LEE, Existence of multiple positive solutions of singular boundary value problems, Nonlinear Anal., 28 (1997), 1429-1438.

[16] G. HAN AND J. WANG, Multiple positive radial solutions of elliptic equations in an exterior domain, Monatsh. Math., 148 (2006), 217-228.

[17] J. JANG, Uniqueness of positive radial solutions of $\Delta u+f(u)=0$ in $\mathbb{R}^{N}, N \geqslant 2$, Nonlinear Anal., 73 (2010), 2189-2198.

[18] E. R. KAUfmanN AND N. Kosmatov, A second order singular boundary value problem, Comput. Math. Appl., 47 (2004), 1317-1326.

[19] L. Kong AND Q. Kong, Nodal solutions of second order nonlinear boundary value problems, Math. Proc. Camb. Phil. Soc., 146 (2009), 747-763.

[20] M. A. KRASNOSEL'SKII, Topological Methods in the Theory of Nonlinear Integral Equations, Pergamon Press, New York, 1964.

[21] X. LIU, Some existence and nonexistence principles for a class of singular boundary value problems, Nonlinear Anal., 27 (1996), 1147-1164.

[22] Z. LIU AND F. LI, Multiple positive solutions of two point boundary value problems, J. Math. Anal. Appl., 203 (1996), 610-624.

[23] H. LÜ AND Z. BAI, Positive radial solutions of a singular elliptic equation with sign changing nonlinearities, Appl. Math. Lett., 19 (2006), 555-567.

[24] R. MA AND B. ThOMPSON, Multiplicity results for second-order two-point boundary value problems with superlinear or sub linear nonlinearities, J. Math. Anal. Appl., 303 (2005), 726-735.

[25] R. MA AND B. THOMPSON, Nodal solutions for nonlinear eigenvalue problems, Nonlinear Anal., 59 (2004), 707-718.

[26] F. I. NJOKU AND F. ZANOLIn, Positive solutions for two point BVP's: Existence and multiplicity results, Nonlinear Anal., 13 (1989), 1329-1338.

[27] R. D. Nussbaum, Periodic solutions of some nonlinear integral equations. Dynamical Systems, (Proc. Internat. Sympos., Univ. Florida, Gainesville, Fla., 1976), Academic Press, New York, (1977), 221-249.

[28] D. O'Regan, Theory of Singular Boundary Value Problems, World Scientific, Singapore, 1994.

[29] J. R. L. WEBB, Uniqueness of the principal eigenvalue in nonlocal boundary value problems, Discrete Contin. Dyn. Syst. Ser. S, 1 (2008), 177-186.

[30] J. R. L. WEBB AND K. Q. LAN, Eigenvalue criteria for existence of multiple positive solutions of nonlinear boundary value problems of local and nonlocal type, Topol. Methods Nonlinear Anal., 27 (2006), 91-116.

[31] E. ZeIDLER, Functional Analysis and its Applications I: Fixed-Point Theorems, Springer-Verlag, New York, 1986.

[32] A. ZetTL, Sturm-Liouville theory, in: Mathematical Surveys and Monographs, Vol. 121, American Mathematical Society, Providence, 2005. 